\title{
Attraction of Spodoptera frugiperda Larvae to Volatiles from Herbivore-Damaged Maize Seedlings
}

\author{
Mark J. Carroll • Eric A. Schmelz • Robert L. Meagher • \\ Peter E. A. Teal
}

Received: 4 January 2006 / Revised: 28 March 2006 /

Accepted: 28 April 2006 / Published online: 11 August 2006

(C) Springer Science + Business Media, Inc. 2006

\begin{abstract}
Plants respond to insect attack with the induction of volatiles that function as indirect plant defenses through the attraction of natural enemies to the herbivores. Despite the fact that volatiles are induced in response to caterpillar attack, their reciprocal effects on the host location behaviors of the same foraging herbivores are poorly understood. We examined orientation responses of sixth instar fall armyworm [FAW; Spodoptera frugiperda (Smith)] to odors from herbivore-damaged and undamaged maize seedlings (Zea mays var. Golden Queen) in y-tube olfactometer bioassays. While both damaged and undamaged maize seedlings were attractive compared with air, sixth instars preferred odors from damaged maize seedlings over odors from undamaged maize seedlings. Gas chromatography-mass spectrometry analysis of plant volatiles revealed that linalool and 4,8-dimethyl-1,3,7nonatriene were the major volatiles induced by FAW herbivory $6 \mathrm{hr}$ after initial damage. Given its prominence in induced plants and established attractiveness to adult FAW, linalool was evaluated both as an individual attractant and as a supplemental component of whole plant odors. Volatile linalool was more attractive than air to sixth instar FAW over a broad range of release rates. FAW also responded selectively to different amounts of linalool, preferring the higher amount. The orientation preferences of FAW were readily manipulated through capillary release of linalool into the airstream of whole plant odors. FAW preferred linalool over undamaged plant odors, and linalool-supplemented plant odors over unsupplemented plant odors, indicating that olfactory preferences could be changed by alteration of a single volatile component. These results suggest that although many induced volatiles attract natural enemies of herbivores, these defenses may also inadvertently recruit more larval herbivores to an attacked plant or neighboring conspecifics.
\end{abstract}

\footnotetext{
The use of trade, firm, or corporation names in this publication (or page) is for the information and convenience of the reader. Such use does not constitute an official endorsement or approval by the United States Department of Agriculture or the Agricultural Research Service of any product or service to the exclusion of others that may be suitable.

M. J. Carroll • E. A. Schmelz $(\bowtie) \cdot$ R. L. Meagher • P. E. A. Teal

Center for Medical, Agricultural, and Veterinary Entomology, U.S. Department of Agriculture,

Chemistry Research Unit, Agricultural Research Service,

1700 SW 23rd Drive, Gainesville, FL 32608, USA

e-mail: eschmelz@gainesville.usda.ufl.edu
} 
Keywords Olfaction · Fall armyworm · Plant-herbivore interactions · Induction · Linalool $\cdot$ Olfactometer

\section{Introduction}

Plants commonly respond to herbivore damage through the synthesis of volatile compounds, a process generally assumed to be detrimental to the herbivore through indirect defense mechanisms (Paré and Tumlinson, 1997, 1999). Induced plant volatiles attract natural enemies of herbivores (Dicke and Sabelis, 1988; Turlings et al., 1990, 1995), indicate the presence of potential competitors, and coincide with the mobilization of direct plant defenses (Karban and Baldwin, 1997). As semiochemicals, induced volatiles may alter the recruitment of herbivores to the damaged host plant, not only by providing chemical cues for host plant location, but also information on the damage status of the host plant (Bernasconi et al., 1998). Behavioral responses of foraging lepidopterans to these cues have been examined primarily in adults because selection of an appropriate host plant for offspring is largely a consequence of female oviposition preferences rather than the consumer (caterpillar) itself (Thompson, 1988). Several species of noctuid moths preferentially oviposit on undamaged rather than damaged plants in response to volatile cues, presumably thus limiting exposure of their offspring to risks of higher predation, parasitism, and competition from older larvae, and performance costs incurred with induced plant defenses (Landolt, 1993; Anderson and Alborn, 1999; De Moraes et al., 2001). Alternatively, some adult coleopterans exploit the relatively greater volatile output of induced plants to locate hosts and conspecifics (Harari et al., 1994; Lougrin et al., 1995; Bolter et al., 1997; Landolt et al., 1999). In both cases, the greater mobility of adults allows for expanded search capabilities for suitable host plants with reduced search time, minimal search costs, and limited exposure to mortality factors (Stamps and Krishnan, 2005; Stamps et al., 2005).

Although adults are the primary life stage for dispersal of most lepidopterans, caterpillars of some species disperse from the original oviposition site and search for new host plants by ballooning (as neonates; Zalucki et al., 2002) or crawling. These larvae forage when suitable food sources are exhausted (Singer and Stireman, 2001), thus avoiding natural enemies (Bernays, 1997; Singer and Stireman, 2003), reducing competitive interactions (Kakimoto et al., 2003), limiting exposure to toxins or balancing nutrients (Singer and Stireman, 2001; Singer et al., 2002), or compensating for suboptimal oviposition choices by females (Beredegué et al., 1992; Roitberg and Mangel, 1993; Doak, 2000). These herbivores rely, to varying degrees, on visual and olfactory cues to orient to new host plants. Despite the fact that volatiles are induced in response to caterpillar attack, their reciprocal effects on the host location behaviors of the same foraging herbivores are poorly understood. The high volatile emissions associated with induced plants may serve as better olfactory cues for host plant location by slow-moving larvae in part through greater chemical apparency (Landolt et al., 2000). Conversely, larvae that select a damaged host plant usually suffer more direct and severe exposure to the deleterious effects of induced defenses and a more restricted ability to move to an alternative host plant than adults (Van Dam et al., 2001). Given the limited choices and greater consequences faced by foraging caterpillars, we investigated larval orientation responses to odors from herbivore-damaged and undamaged host plants in a highly mobile lepidopteran that disperses frequently as a caterpillar.

The fall armyworm (FAW) Spodoptera frugiperda (Smith) is a polyphagous noctuid that feeds on over 60 species of plants and is a periodic, but serious, pest of maize, rice, 
sorghum, turf grasses, cotton, and peanuts (Luginbill, 1928; Sparks, 1979). Larvae often disperse from the original host plant, in part because of frequent and negative effects of overcrowding. Females lay up to 200 eggs in an egg mass on a single host, often exceeding the resources available to offspring (Sparks, 1979; Pitre et al., 1983; Chapman et al., 1999b). Individuals that remain on the original host plant face competition for resources and the threat of cannibalism from conspecifics (Chapman et al., 1999b). At high densities, FAW can completely defoliate their host plants and migrate in search of new hosts en masse, hence the name armyworm (Martin et al., 1980). To compensate, larvae disperse from the oviposition site both within and between host plants. Both neonates and older larvae will move off their host plant if food resources are exhausted or severely degraded by the presence of conspecifics. Despite the polyphagous nature of the species as a whole, selection of an appropriate new host plant can impact larval growth and development. Larval performance of individual FAWs from different host strains varies considerably among host plant species (Pashley, 1988; Meagher et al., 2004) and also can be impacted by previous damage from other herbivores (Bultman and Conard, 1998; Tindall and Stout, 2001). Given that volatiles from herbivoredamaged and undamaged plants differ quantitatively at a minimum, foraging FAW are presented with differences in olfactory cues when making a choice.

We examined FAW responses to herbivore-damaged plants in maize, Zea mays L., a crop plant frequently attacked by this pest. FAW caterpillars preferentially feed on leaf whorls and young seedlings (Davis et al., 1999; Meagher and Nagoshi, 2004), and stimulate the release of copious amounts of induced volatiles in response to caterpillar attack (Gouinguené et al., 2003; Hoballah et al., 2004). The volatile profile of caterpillar-damaged maize changes quantitatively over time as individual volatile components are induced at different rates (Turlings et al., 1998). Roughly speaking, "fresh" damage odors rapidly released by mechanical damage (i.e., green leaf volatiles) can be distinguished from "old" damage odors consisting of terpenoids and other compounds slowly synthesized by the attacked plant (Turlings et al., 1998; Hoballah and Turlings, 2005). We intentionally examined old damage odors because these emissions include induced volatiles that are specifically triggered by insect attack rather than mechanical damage. We also asked whether variation in a single volatile component of old damage odors could alter responses to FAW-damaged plants. The monoterpene linalool is a common constituent of floral and foliar odors that is induced in maize seedlings some hours after initial feeding damage (Turlings et al., 1998). Linalool is attractive to Spodoptera spp. (Carlsson et al., 1999; Jonsson and Anderson, 1999; Deng et al., 2004) and responded to by receptor neurons of noctuid adults (Jonsson and Anderson, 1999; Malo et al., 2004; Røstelien et al., 2005). Given the similarities in adult and larval odorant binding proteins essential to olfaction reception (Laue, 2000) and the profile of FAW-induced volatiles from maize, we evaluated sixth instar FAW responses to linalool both as an individual volatile and a component of whole plant odors.

\section{Methods and Materials}

Plants

We used Z. mays var. Golden Queen, a commercially grown sweet corn variety that, like other sweet corn varieties, is frequently attacked by FAW in Florida (Foster, 1989; Nagoshi and Meagher, 2004). Maize seeds were planted in professional growers mix potting soil (Piedmont Pacific, GA, USA) in 4-in. square pots and maintained under ambient greenhouse light supplemented with high-pressure sodium lamps on a $12 \mathrm{hr}$ light/12 hr 
dark photoperiod. Supplemental lighting was used from 7:00 AM to 7:00 PM. Eleven to 14-d-old seedlings with 3-4 leaves were used in all experiments.

\section{Insects}

Fall armyworms were obtained from a predominantly corn strain colony at Center for Medical, Agricultural, and Veterinary Entomology, U.S. Department of Agriculture-Agricultural Research Service (Gainesville, FL, USA), maintained on a pinto-bean-based artificial diet (King and Leppla, 1984). One of our main concerns was that the larvae obtain sufficient feeding experience on damaged maize before the behavioral bioassays. Previous studies have indicated that prior feeding experience strongly influences both larval orientation and feeding preferences in polyphagous noctuids (Anderson et al., 1995; Carlsson et al., 1999). In preliminary experiments, we noted that naive (pinto-bean-diet-fed) sixth instars had different olfactory preferences toward damaged plants from experienced (maize-fed) sixth instars; however, one night of feeding on maize was sufficient to switch olfactory preferences. To provide larvae with adequate experience, larvae reared on pinto bean diet were transferred at the end of the fifth instar to Golden Queen maize and allowed to feed overnight. Larvae were intentionally placed on maize in sufficient numbers to ensure near total defoliation of host plant material, thereby gaining exposure to heavily damaged plants as might occur at outbreak densities. All larvae were reared at $25^{\circ} \mathrm{C}$ under a $16 \mathrm{hr}$ light $/ 8 \mathrm{hr}$ dark photoperiod.

\section{Treatment of Herbivore-Damaged Maize Seedlings}

To obtain maize seedlings emitting "old" damage odors during the early peak feeding hours of the FAW, each plant was fed upon by 10 sixth instar FAW at 2:00 PM, $6 \mathrm{hr}$ before their use in bioassays or volatile collections later in the evening (8:00 PM). Damage was inflicted under normal light conditions (previously described) to obtain maximal induction of photosynthatedependent volatiles. Larvae were removed after $60 \mathrm{~min}$ to limit both the extent and the time frame of feeding damage.

\section{Plant Volatile Collections}

Because FAW is primarily nocturnal in its feeding activity (Miranda-Anaya et al., 2002), all plant volatile collections were conducted at night several hours after initial damage. Collections of volatiles emitted by maize seedlings were conducted in large glass chambers by using an automated volatile collection system (Analytical Research Systems, Gainesville, FL, USA) modified after Heath and Manukian (1994). Sampling was restricted to aboveground plant structures through the use of a guillotine base. An excess of filtered air $(1 \mathrm{l} / \mathrm{min})$ relative to the vacuum pull was added to the chamber to ensure that outside air did not contaminate volatile sampling. Volatiles were sampled for $1 \mathrm{hr}$ by pulling air at $300 \mathrm{ml} / \mathrm{min}$ over the plants and through a Super Q absorbent filter (80-100 mesh, Alltech Associates, Inc., Deerfield, IL, USA). Volatiles were eluted from the Super Q absorbent with $200 \mu \mathrm{l}$ dichloromethane and $400 \mathrm{ng}$ nonyl acetate as an internal standard.

\section{Identification and Quantification of Plant Volatiles}

Volatile analysis by positive ion electron impact gas chromatography-mass spectrometry was performed on an HP 6890 gas chromatograph coupled to an HP 5973 MS detector. One $\mu \mathrm{l}$ of the sample was injected $\left(240^{\circ} \mathrm{C}\right)$ onto an Agilent HP-5MS dimethylpolysiloxane 
column [30 m $\times 250 \mu \mathrm{m}$ (i.d.) $\times 0.25 \mu \mathrm{m}$, Agilent Technologies, Inc., Palo Alto, CA, USA] and separated by temperatures programmed from $35^{\circ} \mathrm{C}(1.0 \mathrm{~min}$ hold $)$ to $230^{\circ} \mathrm{C}$ at $10^{\circ} \mathrm{C} / \mathrm{min}$. Helium was used as a carrier gas at $1.2 \mathrm{ml} / \mathrm{min}$. Volatiles were identified by comparison of mass spectra with NIST and Department of Chemical Ecology, Gothenburg University (Sweden) mass spectra libraries and retention times with authentic standards.

Quantities of plant volatiles were estimated by using an Agilent $6890 \mathrm{GC}$ coupled to a flame ionization detector $\left(250^{\circ} \mathrm{C}\right)$. One microliter of the sample was injected (splitless, $220^{\circ} \mathrm{C}$ ) onto an Agilent DB-1 dimethylpolysiloxane column $[15 \mathrm{~m} \times 250 \mu \mathrm{m}$ (i.d.) $\times$ $0.25 \mu \mathrm{m}$, Agilent Technologies Inc., Palo Alto, CA, USA] and separated with temperatures programmed from $40^{\circ} \mathrm{C}(0.50 \mathrm{~min}$ hold $)$ to $180^{\circ} \mathrm{C}$ at $12^{\circ} \mathrm{C} / \mathrm{min}$ followed by a $220^{\circ} \mathrm{C}$ post run $(2 \mathrm{~min})$. Helium was used as a carrier gas at $1.2 \mathrm{ml} / \mathrm{min}$.

\section{Y-tube Olfactometer}

The olfactory orientation responses of sixth instar FAW to plant and individual volatile odors were evaluated with a y-tube olfactometer. The experimental choice arena consisted of a horizontal glass y-tube $(7.5 \mathrm{~cm}$ for each arm and base, $15 \mathrm{~cm}$ total length, $10 \mathrm{~mm}$ i.d., $12.7 \mathrm{~mm}$ o.d.; Chemglass, Inc., Vineland, NJ, USA) with different odor sources introduced separately at the distal end of each arm and pulled through the y-tube past the larva by a vacuum line attached at the base. Volatiles were obtained in the airstream by passing prehumidified, carbon-filtered air over the source of the odor. Volatiles were relayed from the distal odor sources to the y-tube arms by 1/4-in. OD corrugated Teflon tubing. Total airflow was maintained and monitored at $150 \mathrm{ml} / \mathrm{min}$ through each arm $(0.08 \mathrm{~km} / \mathrm{hr})$ and $300 \mathrm{ml} / \mathrm{min}(0.16 \mathrm{~km} / \mathrm{hr})$ out of the base of the $\mathrm{y}$-tube by a flowmeter (Aalborg Instruments, Orangeburg, NY, USA)-regulated Tygon vacuum line. To securely connect the glass y-tube to odor source and vacuum lines of differing diameters, rigid Teflon tubing sections of an intermediate diameter were employed as tight-fitting unions. Larvae were prevented from crawling into the odor source lines by a nylon mesh barrier secured between the Teflon union and the glass y-tube. To minimize ambient vibrations that could disturb the larva, each y-tube was secured to a heavy laminate base consisting of white foam board overlaying a brick.

Whole plant odors were sampled by the methods previously described for volatile collection. (-)Linalool (97\% pure, Fluka Chemie AG, Buchs, Switzerland) was introduced into the odor source airstream by capillary release, a method that allows for predictable and stable release of a volatile from a capillary tube based on physiochemical characteristics (Weatherston et al., 1985). Appropriate volatile concentrations were obtained by diverting off and diluting (with filtered air) part of a concentrated odor before it entered the y-tube. The odors were filtered through multiple nylon mesh baffles to thoroughly mix the various volatile components before introduction to the y-tube.

\section{Bioassays}

Because FAW is primarily nocturnal in its peak-feeding activity (Miranda-Anaya et al., 2002), all bioassays and volatile collections were conducted at night. Early sixth instars that had molted within the previous $24 \mathrm{hr}$ were used in the bioassays. These caterpillars were starved for $2 \mathrm{hr}$ before the bioassay to obtain hungry, but mobile, larvae with feeding experience on damaged maize. We initially encountered problems with larvae that did not respond due to handling or ambient vibrations. To minimize direct handling, larvae were transferred to the olfactometer by using a detached piece of the apparatus. A single larva 
was allowed to crawl into the Teflon tube union between the y-tube base and vacuum line, which was reattached in-line. The larva was then given an hour to make a choice between the odors emanating from each arm. Most larvae began moving into the airflow within a few minutes of introduction to the olfactometer. A choice preference for an odor was scored when a larva touched the mesh barrier separating the distal end of the y-tube arm from the odor source line. Larvae that remained completely motionless for $30 \mathrm{~min}$ were assumed to be disturbed by handling and were replaced by a new larva in a fresh Teflon tube union. Larvae that moved but did not make a choice within $1 \mathrm{hr}$ were scored as neutral nonresponders and were excluded from the statistical analysis. Few larvae that moved failed to make a choice $(<5 \%)$ - This low rate probably occurred because the method used to introduce each larva (crawling into a tube) favored actively mobile caterpillars. Up to 10 larvae were run in parallel in separate y-tube olfactometers.

All parts of the y-tube apparatus between the odor source and vacuum line were cleaned or replaced between bioassay trials to remove contaminants. Both the glassware and Teflon parts were thoroughly rinsed with successive washes of acetone, ethanol, ethanol-water, and Milli-Q-filtered water (Millipore, Inc., Billerica, MA, USA) to remove volatiles. Glassware was dried for $1 \mathrm{hr}$ in a $160^{\circ} \mathrm{C}$ oven while Teflon parts were dried for at least $1 \mathrm{hr}$ in a strong laminar air flow (90 1/min).

\section{Statistics}

The preference ratios obtained in the bioassays were compared for departure from a random distribution by a two-tailed binomial exact test. Neutral responses were excluded from the

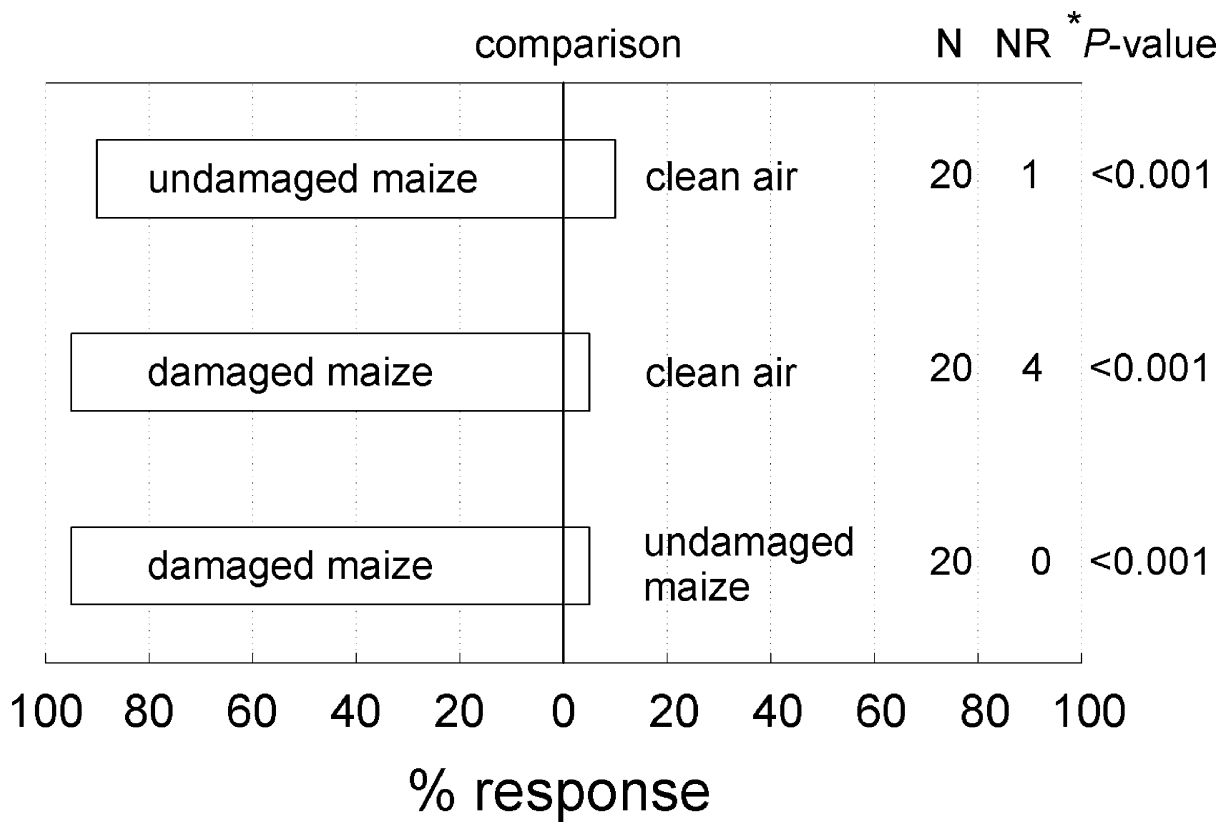

Fig. 1 Orientation responses of sixth instar S. frugiperda to FAW-damaged and undamaged maize seedling odors and clean air controls presented in a y-tube olfactometer. NR - number of neutral or nonresponding larvae that moved but did not score a preference for one of the odor within $1 \mathrm{hr}$. *, probability of ratio departure from a random distribution, two-tailed binomial exact test (neutral responses excluded) 
analyses. Volatile component release rates were compared by a Student's $t$-test (JMP 4.0.4, SAS Institute Inc., Cary, NC, USA).

\section{Results}

Sixth instars were strongly attracted to plant odors in the olfactometer bioassays, regardless of damage status (Fig. 1). In a direct comparison, FAW preferred odors from damaged plants over those of undamaged plants (Fig. 1).

In a comparison of volatiles collected from attacked and undamaged plants $6 \mathrm{hr}$ after damage, the major induced compounds were linalool and (3E)-4,8-dimethyl-1,3,7nonatriene (Fig. 2). Among the 13 volatiles quantified, $(E)$-2-hexenal, myrcene, $(Z)$-3hexenyl acetate, $(E)$ - $\beta$-ocimene, linalool, (3E)-4,8-dimethyl-1,3,7-nonatriene, bergamotene, $\alpha$-humulene, and $(3 E, 7 E)-4,8,12$-trimethyl-1,3,7,11-tridecatetraene were significantly induced (Fig. 2). Other volatiles may be induced at different times after damage. Lipoxygenase products, collectively known as the green leaf volatiles, were not prominently induced at this late time point because their peak induction in maize occurs immediately after damage, then rapidly declines (Turlings et al., 1998; Hoballah and Turlings, 2005).

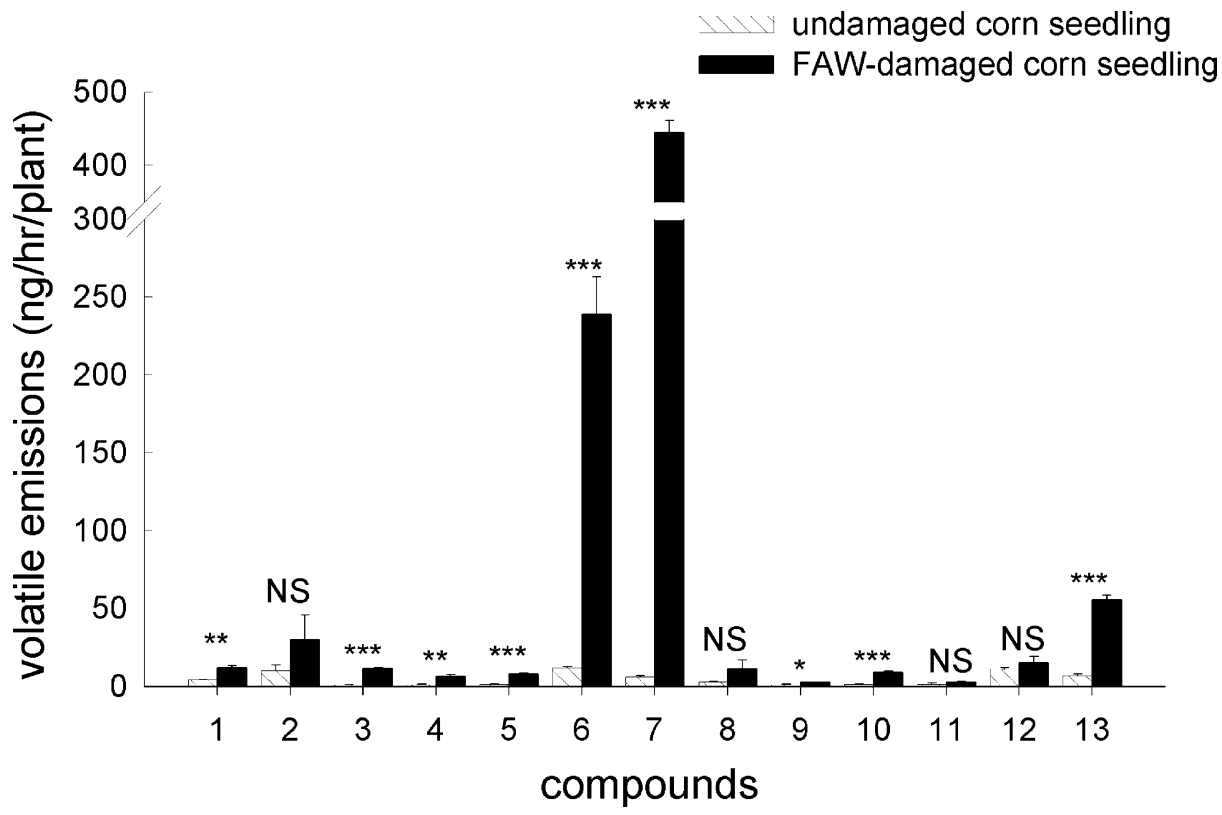

Fig. 2 Average nighttime volatile emission rates $(+$ S.E., $N=4)$ of 13 compounds from undamaged and FAW-damaged maize seedlings ( $Z$. mays var. Golden Queen) $1 \mathrm{hr}$ into the scotophase. Damaged plants were fed on for $1 \mathrm{hr}$ by 10 sixth instar FAWs, $5 \mathrm{hr}$ before the onset of scotophase. $* P<0.05, * * P<0.01,{ }^{* * *} P<$ 0.001 , NS (not significant) $P>0.05$ by Student's $t$-test. (1) $(E)$-2-hexenal; (2) (Z)-3-hexen-1-ol; (3) $\beta$ myrcene; (4) (Z)-3-hexenyl acetate; (5) (E)- $\beta$-ocimene; (6) linalool; (7) (3E)-4,8-dimethyl-1,3,7-nonatriene; (8) indole; (9) $(E)$ - $\alpha$-bergamotene; (10) $\alpha$-humulene; (11) $(E)$ - $\beta$-farnesene; (12) $(E)$-nerolidol; $(13)(3 E, 7 E)$ 4,8,12-trimethyl-1,3,7,11-tridecatetraene 
Linalool was an olfactory attractant to sixth instars in the olfactometer bioassays. They were attracted to linalool rather than clean air over a broad range of volatile emissions (Fig. 3). When two release rates were presented in the olfactometer, FAW preferred the higher amount (Fig. 3). These results indicate that FAW is capable of discerning between and responding to different aerial concentrations of linalool, such as would be encountered between induced and uninduced plants.

Direct manipulation of an odor source airstream with capillary-released linalool was sufficient to alter, and in some cases, supplant orientation preferences toward whole plant odors. We first evaluated the effect of linalool supplementation on FAW responses to two split-flow airstreams originating from an undamaged plant. FAW did not demonstrate a significant preference for either airstream without supplementation, both sides representing equivalent proportions of emissions from the common source (Fig. 4). By contrast, FAW preferred a linalool-supplemented plant odor rather than an unsupplemented one (Fig. 4). In a direct comparison of odors from an undamaged maize seedling against linalool introduced at release rates equivalent to an undamaged plant, FAW significantly preferred linalool (Fig. 4).

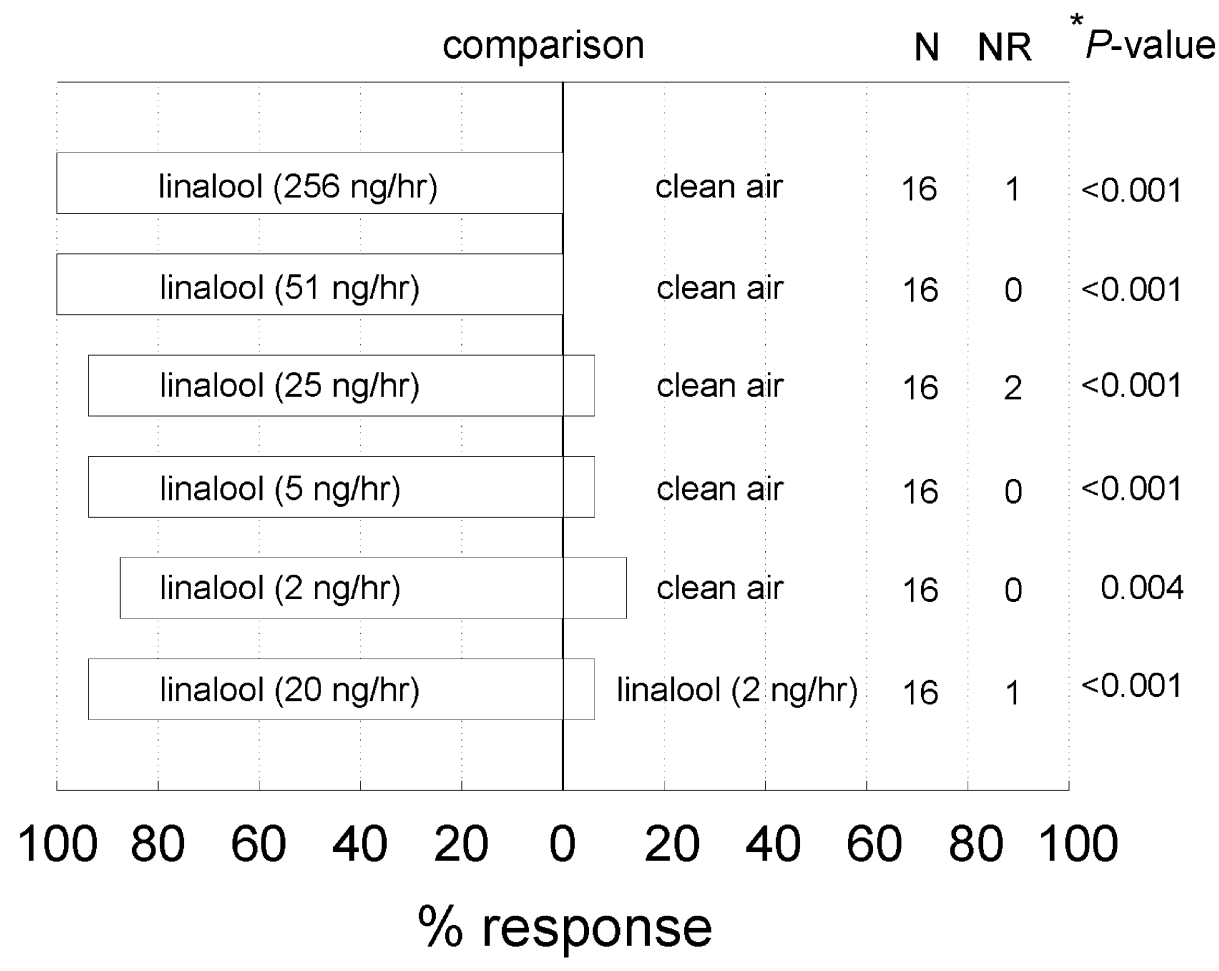

Fig. 3 Orientation responses of sixth instar $S$. frugiperda to linalool and clean air controls presented in a ytube olfactometer. Linalool release rates $(\mathrm{ng} / \mathrm{hr})$ measured for each odor source immediately before the bioassay are given in parentheses. NR - number of neutral or nonresponding larvae that moved but did not score a preference for one of the odor within $1 \mathrm{hr}$. *, probability of ratio departure from a random distribution, two-tailed binomial exact test (neutral responses excluded) 


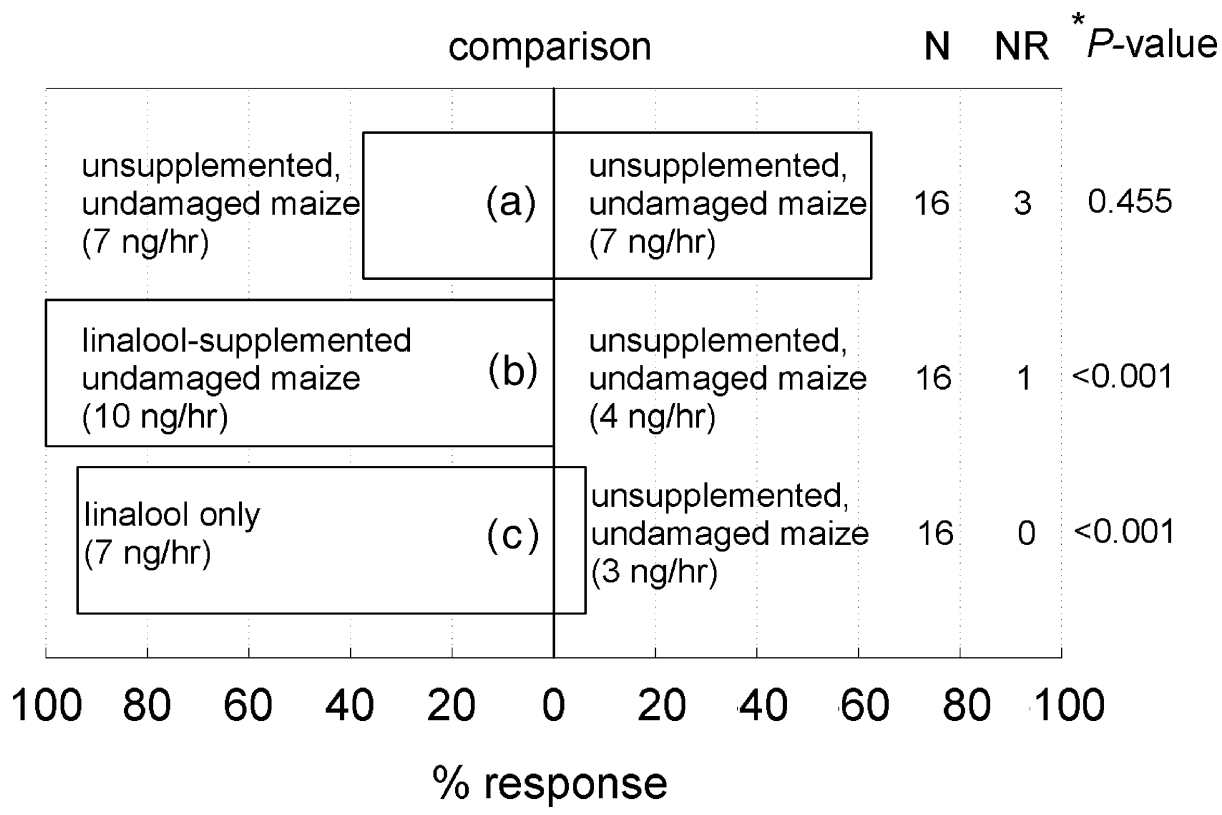

Fig. 4 Orientation responses of sixth instar $S$. frugiperda in y-tube olfactometer trials to (a) equivalent undamaged maize seedling odors originating from a single source divided by a split air flow apparatus; (b) linalool-supplemented, and unsupplemented, undamaged maize seedling odors originating from a single source divided by a split air flow apparatus; or (c) linalool and an unsupplemented, undamaged maize seedling odor. Linalool release rates (ng/hr) measured for each odor source immediately before the bioassay are given in parentheses. NR - number of neutral or nonresponding larvae that moved but did not score a preference for one of the odor within $1 \mathrm{hr}$. *, probability of ratio departure from a random distribution, twotailed binomial exact test (neutral responses excluded)

\section{Discussion}

The olfactory orientation preferences of sixth instars for linalool over whole undamaged plant odors indicate that a single volatile component can alter preferences toward damaged-plant odors. These preferences could be attributed to attraction to higher amounts of linalool in damaged plants (against undamaged plants) and in the supplemented airstream (against undamaged plants). Our bioassays demonstrated that sixth instars responded favorably to a 10fold difference in capillary-released linalool concentration (2 $\mathrm{ng} / \mathrm{hr}$ against $20 \mathrm{ng} / \mathrm{hr}$ ), of relevance to the average amounts released by undamaged $(12 \mathrm{ng} / \mathrm{hr})$ and induced $(239 \mathrm{ng} / \mathrm{hr})$ maize seedlings. Our split flow bioassays demonstrate that a preference developed as a result of the addition of an attractant to otherwise equivalent, if already attractive, odor streams. If strong orientation biases for individual volatile components over the plant odor exist, such olfactory preferences could be exploited in trap crop strategies designed to move insects away from valuable crop tissues to expendable plants (Shelton and Badenes-Perez, 2006).

However, linalool is unlikely to be the only volatile from maize seedlings that could evoke behavioral responses in sixth instar FAW, due in part to the role of feeding experience in orientation behaviors of generalist noctuid larvae. Olfactory preferences of polyphagous noctuids, such as FAW, are strongly influenced by exposure to odors during feeding (Anderson et al., 1995; Carlsson et al., 1999; Glendinning, 2002). Experience-based preferences are thought to confer a certain degree of behavioral plasticity on the development of host location 
and feeding cues in individual generalist larvae that feed preferentially on specific hosts. Carlsson et al. (1999) demonstrated that either linalool or geraniol could serve as olfactory attractants to third instar Spodoptera littoralis, provided that the larvae had previous feeding experience in the presence of the volatile. We contend that while linalool is an olfactory attractant to experienced sixth instars, other induced volatiles may serve a similar role in preferences for damaged maize seedlings and should be evaluated as such in future studies.

Perhaps the most striking aspect of our results is that sixth instars are strongly attracted to herbivore-damaged rather than undamaged host plant odors, despite the disadvantages of association with a damaged host plant (Bolter et al., 1997) and the intensity of densitydependent mortality factors in this species. Like many caterpillars, FAW experiences significantly higher predation rates in association with severely damaged plants (Chapman et al., 2000). Several major parasitoids of FAW have been shown to be specifically attracted to volatiles from caterpillar-damaged maize (Turlings et al., 1995; Gouinguené et al., 2005; Hoballah and Turlings, 2005). Furthermore, intraspecific competition and conflict are intense in later FAW instars. FAW frequently engages in cannibalism even when food resources are adequate, resulting in an estimated $40 \%$ to $60 \%$ mortality rate among larvae (Chapman et al., 1999a). Consequently, later instars rarely cohabit in the same leaf whorl and readily attack conspecifics, particularly younger instars. Chapman et al. (1999b) noted that the mere presence of conspecifics reduced larval performance, even when cannibalism was prevented. One consolatory benefit of sixth instar preferences for damaged plants is that asymmetrical encounters between foraging sixth instars and any earlier instar occupying the damage site is likely to favor the older instar (Chapman et al., 1999b; Kakimoto et al., 2003). Otherwise, the advantages of being attracted to a damaged plant when there is an undamaged alternative remain unclear.

One mechanistic constraint that favors attraction to damaged plant odors is the extent of prior feeding experience on attacked plants. Caterpillars feed primarily on attacked plant tissues previously damaged by themselves. Induction of monoterpenes in maize is highly localized to the wounded leaf rather than the whole plant (Turlings and Tumlinson, 1992), so a sixth instar feeding on different leaves experiences repeated inductions of monoterpenes, including linalool, as part of its olfactory experience. Future studies should examine whether plant-reared larvae that are prevented from experiencing induced volatiles (i.e., by frequent movement or use of a mutant host plant deficient in induced volatile responses) prefer herbivore-damaged plants over undamaged plants. Due to their reliance on experience as a mechanism for preference, polyphagous caterpillars such as FAW may fail to realize an optimal choice (orient to a undamaged seedling) because of preferences for more familiar host odors.

Because volatiles of attacked and unattacked Golden Queen maize seedlings vary quantitatively, but not qualitatively, it is not clear whether the observed responses indicate a true orientation preference for damaged plants or simply attraction to a greater source of host volatiles. Orientation to higher amounts of volatile attractants may serve as a mechanism for assessing how close two volatile sources are to the foraging caterpillar, with damaged plants appearing "closer" by virtue of higher volatile output. Other foraging caterpillars use appearance for relative assessment, rather than direct measurement, of distance to select between two competing stimuli. Diurnally foraging caterpillars that orient visually to host plant shapes cannot distinguish between nearby small objects and distant large objects that appear to be of the same size (share the same visual angle; Saxena and Khattar, 1977; Marchand and McNeil, 2004).

Paradoxically, a preference for odors from suboptimal, but detectable, damaged hosts might be a behavioral strategy to cope with the uncertainties of host plant location. Foragers that experience high mortality and costs while searching for ephemeral hosts can be expected to have host-seeking behaviors that emphasize detectability over quality (Ward, 
1987; Stamps and Krishnan, 2005; Stamps et al., 2005). In contrast to highly mobile flying adults, the set of potential hosts available to a foraging caterpillar is greatly reduced and widely dispersed due to the "small-scale" search capabilities imposed by the slow speed of crawling (Singer and Stireman, 2001; Stamps et al., 2005). To a foraging caterpillar with limited mobility and search capabilities, the costs encountered with not locating an appropriate host plant may outweigh the risks associated with an induced host plant. Caterpillars searching for a new host plant face mortality from predation, exposure, and starvation as well as sublethal opportunity costs incurred by slow search capabilities and uncertain quality of the new host plant (Sih, 1993; Zalucki et al., 2002; Kaitaniemi et al., 2004). Foraging neonate codling moth Cydia pomonella prefer odors from apples damaged by conspecifics over undamaged fruits, in part because damaged fruit release greater amounts of the olfactory attractants, such as $\alpha$-farnescene, that increase detectability (Landolt et al., 2000). Induced volatiles from an attacked maize seedling may be more apparent, and, therefore, more reliable, olfactory cues for a foraging FAW caterpillar. An emphasis on reliability and detectability at the expense of quality may also explain olfactory preferences for widely produced but relatively nonspecific volatile cues such as linalool by FAW (Stamps and Krishnan, 2005; Stamps et al., 2005). Attraction to induced volatiles may be particularly advantageous to foraging FAWs in the location of host plants that occur in patchy distributions, including agroecosystem and pasture monocultures. Enhanced foraging success may occur directly through perception of the greater aggregate volatile output produced by several neighboring damaged plants, or indirectly through the association of undamaged plants with induced volatile cues from highly detectable herbivore-damaged conspecifics (associational susceptibility; Rodriguez-Saona and Thaler, 2005).

Attraction to a damaged host plant may also be advantageous if the caterpillar can evade some of the consequences associated with induced tissues by feeding away from the damage site. Although our results indicate that sixth instar FAW preferentially orient to the odors of herbivore-damaged plants over undamaged plants, it remains unknown if these preferences hold once the caterpillar locates and comes into contact with the plant. The olfactory preferences reported here may represent a mechanism for host plant location, but not necessarily host acceptance and feeding. Orientation to a distant host plant by definition is restricted to sensory modalities that do not require contact. By contrast, acceptance of a host plant and establishment of a feeding site on a plant involves feeding stimuli received from olfactory, gustatory, and tactile assessment of the tissue (Schoonhoven and van Loon, 2002). Host plant location and acceptance behaviors toward damaged plants are partially decoupled in other lepidopterans. Studies on related noctuid caterpillars in other plants indicate that larvae tend to move away from herbivore-damaged or induced plant tissues, if they move at all on the plant (McAuslane and Alborn, 2000; Anderson et al., 2001). Female Trichoplusia ni moths orient toward herbivore-damaged rather than undamaged plants, but preferentially oviposit on undamaged plants when given a choice (Landolt, 1993, 2001). Our preliminary observations indicate that sixth instar FAWs do not display strong preferences for damaged leaves over undamaged leaves when they select an initial feeding site. Such a switch in behavioral responses to damage would be consistent with changes in risk assessment expected for dispersers (Stamps and Krishnan, 2005; Stamps et al., 2005)_Once a host plant is contacted by a foraging caterpillar, the risks associated with host plant location and foraging diminish, leaving only the disadvantages inherent in an herbivore-damaged plant.

Acknowledgments We thank Hans Alborn, Sean Collins, Art Zangerl, and two anonymous reviewers for helpful comments that improved the manuscript. We also thank Julia Meredith, Nancy Lowman, and Valerie McManus for assistance in the maintenance of plants and insects used in this experiment. 


\section{References}

Anderson, P. and Alborn, H. 1999. Effects on oviposition behaviour and larval development of Spodoptera littoralis by herbivore-induced changes in cotton plants. Entomol. Exp. Appl. 92:45-51.

Anderson, P., Hilker, M., and LöFQVIST, J. 1995. Larval diet influence on oviposition behavior in Spodoptera littoralis. Entomol. Exp. Appl. 74:71-82.

Anderson, P., Jonsson, M., and MorTe, U. 2001. Variation in damage to cotton affecting larval feeding preference of Spodoptera littoralis. Entomol. Exp. Appl. 101:191-198.

Beredegué, M., Reitz, S. R., and Trumble, J. T. 1992. Host plant selection and development in Spodoptera exigua: Do mother and offspring know best? Entomol. Exp. Appl. 89:57-64.

Bernasconi, M. L., Turlings, T. C. J., Ambrosetti, L., Bassetti, P., and Dorn, S. 1998. Herbivoreinduced emissions of maize volatiles repel the corn leaf aphid, Rhopalosiphum maidis. Entomol. Exp. Appl. 87:133-142.

BERnAYS, E. A. 1997. Feeding by lepidopteran larvae is dangerous. Ecol. Entomol. 22:121-123.

Bolter, C. J., Dicke, M., VAn Loon, J. J. A., Visser, J. H., and Posthumus, M. A. 1997. Attraction of Colorado potato beetle to herbivore-damaged plants during herbivory and after its termination. J. Chem. Ecol. 23:1003-1023.

Bultman, T. L. and CONARD, N. J. 1998. Effects of endophytic fungus, nutrient level, and plant damage on performance of fall armyworm (Lepidoptera: Noctuidae). Environ. Entomol. 27:631-635.

Carlsson, M. A., Anderson, P., Hartlieb, E., and Hansson, B. S. 1999. Experience-dependent modification of orientational response to olfactory cues in larvae of Spodoptera littoralis. J. Chem. Ecol. 25:2445-2454.

Chapman, J. W., Williams, T., Escribano, A., Caballero, P., Cave, R. D., and Goulson, D. 1999a. Age-related cannibalism and horizontal transmission of a nuclear polyhedrosis virus in larval Spodoptera frugiperda. Ecol. Entomol. 24:268-275.

Chapman, J. W., Williams, T., Escribano, A., Caballero, P., Cave, R. D., and Goulson, D. 1999 b. Fitness consequences of cannibalism in the fall armyworm, Spodoptera frugiperda. Behav. Ecol. 10:298-303.

Chapman, J. W., Williams, T., Martinez, A. M., Cisneros, J., Caballero, P., Cave, R. D., and Goulson, D. 2000. Does cannibalism in Spodoptera frugiperda (Lepidoptera: Noctuidae) reduce the risk of predation? Behav. Ecol. Sociobiol. 48:321-327.

Davis, F. M., Williams, W. P., Chang, Y. M., BAKER, G. T., and Hedin, P. A. 1999. Differential growth of fall armyworm larvae (Lepidoptera: Noctuidae) reared on three phenotypic regions of whorl leaves from a resistant and a susceptible maize hybrid. Fla. Entomol. 82:248-254.

De Moraes, C. M., Mescher, M. C., and Tumlinson, J. H. 2001. Caterpillar-induced nocturnal plant volatiles repel nonspecific females. Nature 410:577-580.

DENG, J. Y., WEI, H. Y., HuANG, Y. P., and DU, J. W. 2004. Enhancement of attraction to sex pheromones of Spodoptera exigua by volatile compounds produced by host plants. J. Chem. Ecol. 30:2037-2045.

Dicke, M. and SABELIS, M. W. 1988. How plants obtain predatory mites as bodyguards. Neth. J. Zool. $38: 148-165$.

DoAK, P. 2000. Population consequences of restricted dispersal for an insect herbivore in a subdivided habitat. Ecology 81:1828-1841.

FosTER, R. E. 1989. Strategies for protecting sweet corn ears from damage by fall armyworms (Lepidoptera: Noctuidae) in Southern Florida. Fla. Entomol. 72:146-151.

GLENDINNING, J. I. 2002. How do herbivorous insects cope with noxious secondary plant compounds in their diet? Entomol. Exp. Appl. 104:15-25.

GouinguenÉ, S., Alborn, H., and Turlings, T. C. J. 2003. Induction of volatile emissions in maize by different larval instars of Spodoptera littoralis. J. Chem. Ecol. 29:145-162.

Gouinguené, S., Pickett, J. A., Wadhams, L. J., Birkett, M. A., and Turlings, T. C. J. 2005. Antennal electrophysiological responses of three parasitic wasps to caterpillar-induced volatiles from maize (Zea mays mays), cotton (Gossypium herbaceum), and cowpea (Vigna unguiculata). J. Chem. Ecol. 31:1023-1038.

HARARI, A. R., Ben-YAKIR, D., and Rosen, D. 1994. Mechanism of aggregation behavior in Maladera matrida Argaman (Coleoptera: Scarabidae). J. Chem. Ecol. 20:361-371.

HeAth, R. R. and ManuKian, A. 1994. An automated-system for use in collecting volatile chemicals released from plants. J. Chem. Ecol. 20:593-608.

Hoballah, M. E. and Turlings, T. C. J. 2005. The role of fresh versus old leaf damage in the attraction of parasitic wasps to herbivore-induced maize volatiles. J. Chem. Ecol. 31:2003-2018.

Hoballah, M. E., Kollner, T. G., Degenhardt, J., and Turlings, T. C. J. 2004. Costs of induced volatile production in maize. Oikos 105:168-180. 
Jonsson, M. and Anderson, P. 1999. Electrophysiological response to herbivore-induced host plant volatiles in the moth Spodoptera littoralis. Physiol. Entomol. 24:377-385.

Kaitaniemi, P., Vehvilainen, H. and RuohomaKi, K. 2004. Movement and disappearance of mountain birch defoliators are influenced by the interactive effects of plant architecture and induced resistance. Ecol. Entomol. 29:437-446.

Kakimoto, T., Fujisaki, K., and Miyatake, T. 2003. Egg laying preference, larval dispersion, and cannibalism in Helicoverpa armigera (Lepidoptera: Noctuidae). Ann. Entomol. Soc. Am. 96:793-798.

KARBAN, R. and BALDWIN, I. 1997. Induced Responses to Herbivory. University of Chicago Press, Chicago, IL.

KING, E. G. and LePPLA, N. C. 1984. Advances and Challenges in Insect Rearing. U.S. Government Printing Office.

LANDOLT, P. J. 1993. Effects of host plant leaf damage on cabbage moth attraction and oviposition. Entomol. Exp. Appl. 67:79-85.

LANDOLT, P. J. 2001. Moth experience and not plant injury affected female cabbage looper moth (Lepidoptera: Noctuidae) orientation to potato plants. Fla. Entomol. 84:243-249.

Landolt, P. J., Tumlinson, J. H., and Alborn, D. H. 1999. Attraction of Colorado potato beetle (Coleoptera: Chrysomelidae) to damaged and chemically induced potato plants. Environ. Entomol. 28:973-978.

Landolt, P. J., Brumley, J. A., Smithhisler, C. L., Biddick, L. L., and Hofstetter, R. W. 2000. Apple fruit infested with codling moth are more attractive to neonate codling moth larvae and possess increased amounts of (E,E)-alpha-farnesene. J. Chem. Ecol. 26:1685-1699.

LAUE, M. 2000. Immunolocalization of general odorant-binding protein in antennal sensilla of moth caterpillars. Arthropod Struct. Dev. 29:57-73.

Lougrin, J. H., PotTer, D. A., and HAmilton-Kemp, T. R. 1995. Volatile compounds induced by herbivory act as aggregation kairomones for the Japanese beetle (Popilia japonica Newman). J. Chem. Ecol. 21:1457-1467.

LuginbiLl, P. 1928. The fall armyworm. U.S. Dept Agric. Tech. Bull. 34:1-91.

Malo, E. A., Castrejon-Gomez, V. R., CruZ-Lopez, L., and Rojas, J. C. 2004. Antennal sensilla and electrophysiological response of male and female Spodoptera frugiperda (Lepidoptera: Noctuidae) to conspecific sex pheromone and plant odors. Ann. Entomol. Soc. Am. 97:1273-1284.

Marchand, D. and MCNEIL, J. N. 2004. The importance of behavioral plasticity for maximizing foraging efficiency in frugivorous lepidopteran larvae. J. Insect Behav. 17:673-684.

MARTIN, P., WiSEMAN, B., and LYNCH, R. 1980. Action thresholds for fall armyworm on grain sorghum and coastal Bermuda grass. Fla. Entomol. 63:375-404.

McAuslane, H. J. and AlboRn, H. T. 2000. Influence of previous herbivory on behavior and development of Spodoptera exigua larvae on glanded and glandless cotton. Entomol. Exp. Appl. 97:283-291.

MeAgher, R. L. and NAgoshi, R. N. 2004. Population dynamics and occurrence of Spodoptera frugiperda host strains in southern Florida. Ecol. Entomol. 29:614-620.

Meagher, R. L., Nagoshi, R. N., Stuhl, C., and Mitchell, E. R. 2004. Larval development of fall armyworm (Lepidoptera: Noctuidae) on different cover crop plants. Fla. Entomol. 87:454-460.

Miranda-Anaya, M., Guevara-Fefer, P., and Garcia-Rivera, B. E. 2002. Circadian locomotor activity in the larva and adult fall armyworm, Spodoptera frugiperda (Noctuidae): Effect of feeding with the resistant variety of maize CML67. Biol. Rhythm Res. 33:475-486.

NAGOSHI, R. N. and MEAGHER, R. L. 2004. Behavior and distribution of the two fall armyworm host strains in Florida. Fla. Entomol. 87:440-449.

Paré, P. W. and Tumlinson, J. H. 1997. Induced synthesis of plant volatiles. Nature 385:30-31.

Paré, P. W. and Tumlinson, J. H. 1999. Plant volatiles as a defense against insect herbivores. Plant Physiol. $121: 325-331$.

PASHLEY, D. P. 1988. Quantitative genetics, development, and physiological adaptation in host strains of fall armyworm. Evolution 42:93-102.

Pitre, H. N., Mulrooney, J. E., and HogG, D. B. 1983. Fall armyworm (Lepidoptera: Noctuidae) oviposition: Crop preferences and egg distribution on plants. J. Econ. Entomol. 76:463-466.

RodrigueZ-SAONA, C. and THALER, J. S. 2005. Herbivore-induced responses and patch heterogeneity affect abundance of arthropods on plants. Ecol. Entomol. 30:156-163.

Roitberg, B. D. and MAngel, M. 1993. Parent-offspring conflict and life history consequences in herbivorous insects. Am. Nat. 1442:443-456.

Røstelien, T., Stranden, M., Borg-Karlson, A. K., and Mustaparta, H. 2005. Olfactory receptor neurons in two heliothine moth species responding selectively to aliphatic green leaf volatiles, aromatic compounds, monoterpenes and sesquiterpenes of plant origin. Chem. Senses 30:443-461.

SaXenA, K. N. and KhatTAR, P. 1977. Orientation of Papilio demoleus larvae in relation to size, distance, and combination pattern of visual stimuli. J. Insect Physiol. 23:1421-1428. 
Schoonhoven, L. M. and VAN LoON, J. J. A. 2002. An inventory of taste in caterpillars: Each species its own key. Acta Zool. Acad. Sci. Hung. 48:215-263.

Shelton, A. M. and BADENES-PereZ, F. R. 2006. Concepts and applications of trap cropping in pest management. Annu. Rev. Entomol. 51:285-308.

SIH, A. 1993. Effects of ecological interactions on forager diets: Competition, predation risk, parasitism, and prey behavior, pp 182-212, in R. N. Hughes (ed.). Diet Selection: An Interdisciplinary Approach to Foraging Behavior. Blackwell, Oxford.

Singer, M. S., BERNAYS, E. A., and CARRIERE, Y. 2002. The interplay between nutrient balancing and toxin dilution in foraging by a generalist insect herbivore. Anim. Behav. 64:629-643.

SingeR, M. S. and StiReman, J. O. 2001. How foraging tactics determine host-plant use by a polyphagous caterpillar. Oecologia 129:98-105.

Singer, M. S. and StiReman, J. O. 2003. Does anti-parasitoid defense explain host-plant selection by a polyphagous caterpillar? Oikos 100:554-562.

Sparks, A. N. 1979. A review of the biology of the fall armyworm. Fla. Entomol. 62:82-86.

STAMPS, J. and KRISHNAN, V. V. 2005. Nonintuitive cue use in habitat selection. Ecology 86:2860-2867.

StAmps, J. A., Krishnan, V. V., and REID, M. L. 2005. Search costs and habitat selection by dispersers. Ecology 86:510-518.

THOMPSON, J. N. 1988. Evolutionary ecology of the relationship between oviposition preference and performance of offspring in phytophagous insects. Entomol. Exp. Appl. 47:3-14.

Tindall, K. V. and Stout, M. J. 2001. Plant-mediated interactions between the rice water weevil and fall armyworm in rice. Entomol. Exp. Appl. 101:9-17.

TurLingS, T. C. and Tumlinson, J. H. 1992. Systemic release of chemical signals by herbivore-injured corn. Proc. Natl. Acad. Sci. U.S.A. 89:8399-8402.

TurLings, T. C. J., TumLinson, J. H., and LeWIS, W. J. 1990. Exploitation of herbivore-induced plant odors by host-seeking wasps. Science 250:1251-1253.

Turlings, T. J. C., Loughrin, J. H., MCCall, P. J., Rose, U. S., Lewis, W. J., and Tumlinson, J. H. 1995. How caterpillar-damaged plants protect themselves by attracting parasitic wasps. Proc. Natl. Acad. Sci. U.S.A. $92: 4169-4174$.

Turlings, T. C. J., Lengwiler, U. B., Bernasconi, M. L., and Wechsler, D. 1998. Timing of induced volatile emissions in maize seedlings. Planta 207:146-152.

VAN DAM, N. M., HERMENAU, U., and BALDWIN, I. T. 2001. Instar-specific sensitivity of specialist Manduca sexta larvae to induced defences in their host plant Nicotiana attenuata. Ecol. Entomol. 26:578-586.

WARD, S. A. 1987. Optimal habitat selection in time-limited dispersers. Am. Nat. 129:568-579.

Weatherston, I., Miller, D., and Dohse, L. 1985. Capillaries as controlled-release devices for insect pheromones and other volatile substances - a reevaluation. Part I. Kinetics and development of predictive model for glass capillaries. J. Chem. Ecol. 11:953-965.

Zalucki, M. P., Clarke, A. R., and Malcolm, S. B. 2002. Ecology and behavior of first instar larval Lepidoptera. Anпu. Rev. Entomol. 47:361-393. 